process can contribute to reduction of waiting times.

\section{Comment}

Contractual obligations to purchasers, fundholding GP's block and individual contracts as well as pressure from referrers and from families are recognised as influences upon response rates and at times a degree of evaluation and management of such external anxieties is required.

The identified criteria represent an articulation and codification of the basic principles which guide the process of allocation. The response rate which follows illustrates that waiting lists can largely be avoided, with $85 \%$ of the total number of referrals being seen within two months. The value of the CPN service with a commitment to rapid response is particularly highlighted; this service which saw nearly half of the referrals was seeing $84 \%$ within four weeks.

We would contend that a process of allocation based upon multi-disciplinary consideration and flexibility allows for maximal use of resources wherein goals of appropriate allocation, efficient response rate and supportive team functioning can be facilitated. As pressures upon services increase, all three of these goals should be recognised.

\section{Acknowledgements}

We thank Paul Johnson, Greg Richardson and Barry Wright for their help in the preparation of this paper.

\section{References}

MARKANTONAKIS, A. \& MATHA. J. (1990) An evaluation of general practitioners' knowledge and satisfaction of a local child and family psychiatric service. Psychiatric Bulletin, 14, 328-329.

National Health Service Health advisory Service (1995) Together We Stand. London: HMSO.

OKE, S. \& MAYER, R. (1991) Referrals to child psychiatry - a survey of staff attitudes. Archives of Disease in Childhood. 66. 862-865.

O'NEILL-BYRNE. K. \& BROWNING. S. M. (1996) Which patients do GPs refer to which professional. Psychiatric Bulletin. 20. 584-587.

THOMPSON, A. \& PLACE, M. (1995) What influences general practitioners' use of child psychiatric services? Psychiatric Bulletin, 19, 10-12.

Sophie Roberts, Registrar in Psychiatry and "Ian Partridge, Social Worker, York Health, Lime Trees, Child and Adolescent and Family Unit, 31 Shipton Road, York YO3 6RE

*Correspondence

\title{
Use of the Care Programme Approach register by an inner- city old age psychiatry team
}

\author{
Jeremy Wallace and C. J. Ball
}

\begin{abstract}
The Care Programme Approach and its accompanying regitter were introduced in response to diliculties encounfered in a young cotult population. This paper describes the use of the register by an old age psychiatry service who do not routinely accept 'gractuate' patients. Few patients had a diagnosts of dementia and most had poychicticic histories in excess of 10 yecrs.
\end{abstract}

The Care Programme Approach (CPA) was introduced in 1993 in response to a number of highly publicised cases among the young adult popu- lation with severe mental illness. Concerns about the 'seamless' working of multiple agencies in the care of a given individual led to the formalising of the care through the use of a Care Programme Approach and its accompanying register (Kingdon, 1994). For old age psychiatrists interagency working has been at the core of their practice for many years. It is the nature of the patient group that they experience multiple problems, medical, psychological and social, which require input from a number of different 
Table 1. Demographic features of patients on Care Programme Approach register $(n=30)$

\begin{tabular}{lc}
\hline & $n(\%)$ \\
\hline Marital status & \\
Single & $10(33.3)$ \\
Married & $6(20)$ \\
Divorced & $4(13.3)$ \\
Widowed & $10(33.3)$ \\
Accommodation & \\
Own home & $6(20)$ \\
Council property & $16(53.3)$ \\
Sheltered accommodation & $3(10)$ \\
Residential care & $3(10)$ \\
Nursing home & $2(6.7)$ \\
Lives alone & $19(63.3)$ \\
Ethnic origin & $28(93.3)$ \\
White & $1(3.3)$ \\
Afro-Caribbean & $1(3.3)$ \\
Unrecorded & \\
\hline
\end{tabular}

Table 2. Diagnoses and length of psychiatric illness

\begin{tabular}{lc}
\hline & $n(\%)$ \\
\hline Diagnoses & $12(40)$ \\
Schizophrenia & $1(3.3)$ \\
Persistent delusional disorder & $1(3.3)$ \\
Schizoaffectlve disorder & $4(13.3)$ \\
Bipolar affective disorder & $10(33.3)$ \\
Recurrent depressive disorder & $2(6.7)$ \\
Dementia (1+schizophrenia) & $1(3.3)$ \\
Korsakov's syndrome & $1(3.3)$ \\
Organic hallucinosis (in a patient & \\
with depression) & $1(3.3)$ \\
Alcohol dependence syndrome (in a & \\
patient with depression) & \\
Length of illness & $19(63.3)$ \\
Greater than 10 years & $6(20)$ \\
5-10 years & $1(3.3)$ \\
1-5 years & $1(3.3)$ \\
Under 1 year (patient with dementia) & \\
\hline
\end{tabular}

agencies and professions. How these agencies and professions work together has been a source of great debate and is very dependent upon local conditions, structures and personalities. Despite this Philpott \& Banerjee (1997) comment upon the lack of published information concerning elders and the CPA register.

While all people in contact with the service are considered for inclusion into the CPA scheme, only a relatively small number will meet the criteria for inclusion onto the register, i.e. a diagnosis of severe and persistent mental illness and any of the following:

(a) A history of repeated relapse of illness due to a breakdown in their medical and social care in the community. (b) A history of serious self-neglect or of violence, and are dangerous to others as a consequence of their illness which clinicians judge to be relevant in view of the patients current or likely future mental health, taking into account their past history.

(c) Individuals who require multi-agency involvement and cooperation.

Some three years after the start of the CPA register it was decided to review the practice of an old age psychiatry service serving an innerLondon area, with high Jarman indices but with some areas of relative affluence, in order to view how the register was working for a service that was used to integrating services and had a population for whom the measure was not primarily intended.

\section{The study}

All the patients over the age of 65 years on the CPA register and under the care of the old age psychiatry services for the trust area on a given day were obtained and the case notes reviewed. The review included demographic features of the population, the indications for inclusion on the CPA register, medication, diagnoses, readmission and a random sample of meetings from each of the case notes was looked at to see who was invited to the meetings and who attended them.

\section{Findings}

The population of over $65 \mathrm{~s}$ in the area is 47200 (1991 census figures). The community teams receive approximately 1100 referrals per year (1995 figures). Graduate patients remain under the care of the adult psychiatric team unless particular problems such as dementia ensue. Thirty patients were identified as being on the CPA register. The demographic details are listed in Table 1.

Men $(n=15)$ and women $(n=15)$ were equally represented with a mean age of 74.2 (range 66$84)$. The majority were White $(28,93.3 \%)$, living alone $(n=19,63.3 \%)$ and usually in their own or council properties $(n=22,73.3 \%)$.

The patient diagnoses are recorded in Table 2. as is the length of their history of mental illness. The total number of diagnoses being more than 30 as two patients had dual diagnoses. One patient who suffered from schizophrenia for many years developed a dementing illness and one patient with a recurrent depressive disorder had alcohol dependence syndrome. What is most remarkable is that only one patient had a primary diagnosis of a dementing illness and also that the majority of the patients had had a history of greater than 10 years of mental illness. 
As a group, many were receiving medication. Seventeen $(56.7 \%)$ were taking antipsychotics of which six (20\%) were via depots, and 17 (56.7\%) were taking antidepressants of varying sorts. Three (10\%) patients were taking no medication at all, although this was less by design than by refusal so to do. Many were also taking drugs for medical indications $(13,43.3 \%)$.

The mean length of time on the register was 14.16 months (range 4-24) with $14(46.7 \%)$ of the patients also subject to Section 117 of the Mental Health Act 1983. Seventeen (56.7\%) were placed on the register as in-patients. Repeated relapse $(22,73.3 \%)$ and self-neglect $(21,70 \%)$ were the most common reasons given for inclusion on the register, with the care coordinators, most commonly community psychiatric nurses $(15,50 \%)$, reflecting the composition of community teams.

Readmissions occurred for eight patients (26.6\%) since their inclusion on the register with a mean of 1.75 (range 1-3) readmissions. This is despite the relatively high levels of symptomatology displayed by these patients when in the community. Eighteen remaining symptomatic $60 \%$. Review of the attendance at the meeting reveals ( $n=28$, no clear records in two cases) an average of 5.3 (range 2-8) people were invited to the meetings but only 4.2 (range 2-5) attended. In two cases it was clear that the general practitioners were not invited to the meetings but in the 26 cases where invitations were offered on only three occasions (12\%) was the general practitioner present. Carers were identified in 19 (63.3\%) of cases and attended $16(84.2 \%)$ of the meetings to which they were invited.

\section{Comment}

Discussions about these results suggest that the CPA register is used for only a relatively small number of patients in this area. This probably represents local practice and may or may not be generalisable to other services. Perhaps the most striking feature, in addition to this relatively low use of the register, is the very few patients who suffer from a primary diagnosis of a dementing illness despite these making up the bulk of referrals to any old age psychiatry service (Philpot \& Banerjee, 1997). This may represent the well-developed traditions of multi-agency working within the area. Particularly in the southern part of the district where a case management scheme, joint funded with the social services, is able to support many vulnerable patients with dementia with intensive domicillary care packages, significantly reducing the risk of self-neglect or self-harm (Philpot \& Banerjee, 1997).

It is encouraging to note that where possible carers are invited to meetings they do frequently attend, as do a wide range of professionals involved in the care of these particularly difficult patients. Despite the regular invitations to general practitioners, they are not coming to the meetings. This may be for a variety of reasons but given the complex nature of the physical, psychological and social problems presented by this group, this is a cause for some concern. It is clearly difficult for busy primary care practitioners to attend meetings (which are often of some length), with the pressures of surgeries and home visits. However, understanding the roles of different practitioners involved in a person's care makes communication very much easier when problems do arise. It may be that solutions such as telephone or video-conferencing facilities (McClaren et al, 1993) could improve 'attendance' at meetings for the many different professionals. The development of joint case registers and other information systems may facilitate integrative working.

It is likely that this survey represents practice at a local level. It is unclear how generalisable the findings are, particularly in relation to the lack of patients with dementia on the register. The guidelines on the use of the CPA are subject to marked local variation dependent upon the nature of the catchment area, the local make up of services (social, voluntary as well as psychiatric) and the individual practice of clinicians. Clearly old age psychiatrists need to look carefully at their practice in relation to the CPA register and over time develop consensus concerning the usefulness of the register to those with a wider range of diagnoses.

\section{References}

Kingdon, D. (1994) Care Programme Approach. Recent government policy and legislation. Psychiatric Bulletin. 18. 68-70.

MCClaREN. P. M., BALl. C. J., BRostoff, E., et al (1993) Moving towards Europe: clinical conferencing via the telephone. Journal of the Royal Society of Medicine, 86. 523-526.

PhILPOT, M. \& BANERJEe. S. (1997) Mental health services for older people in London. In London's Mental Health. The Report for the King's Fund London Commission leds S. Johnson, R. Ramsay, G. Thornicroft, et al. London: King's Fund Publishing.

Jeremy Wallace, Senior House Officer in Old Age Psychiatry, Lewisham and Guy's Mental Health NHS Trust, Hither Green Hospital, London and C. J. Ball, Consultant and Senior Lecturer in Old Age Psychiatry, Lewisham and Guy's Mental Health NHS Trust and United Medical and Dental Schools, Division of Psychiatry and Psychology, Guy's Hospital, London

Correspondence: Dr C. J. Ball, Mental Health in the Elderly Community Team B, 59 Cordwell Road, London SE13 5QY 